\title{
O CONHECIMENTO MUSICAL DOS PROFESSORES GENERALISTAS DE ALGUMAS ESCOLAS MUNICIPAIS DE PRESIDENTE PRUDENTE - SP: UM ESTUDO DE CASO
}

Patrícia Mertzig Gonçalves de Oliveira ${ }^{1}$, Luciana Carolina Fernandes de Faria, Carlos Rogério Frangiotti ${ }^{2}$,Cristiani Maria Faccio ${ }^{2}$,Ivanilde Lourdes Matsu ${ }^{2}$,Maria Eliza de Oliveira ${ }^{2}$,Sueli Felicio Fernandes ${ }^{2}$, Taiane Helena Miele Perucci².

${ }^{1}$ Docentes do curso de Licenciatura em Música da Universidade do Oeste Paulista - UNOESTE. ${ }^{2}$ Discentes do curso de Licenciatura em Música da Universidade do Oeste Paulista - UNOESTE.

\section{RESUMO}

O presente artigo tem por objetivo analisar o conhecimento musical dos professores generalistas de algumas escolas da rede municipal de educação da cidade de Presidente Prudente - SP. Para tanto foram selecionadas 10 escolas da rede municipal e, por meio de entrevista semiestruturada, os professores responsáveis pela Educação Infantil e Ensino fundamental I foram questionados sobre o que compreendem sobre Educação Musical e como fazem para abordar a música em sua prática em sala de aula, bem como suas principais dúvidas e dificuldades. Como resultado, foi concluído que os professores entrevistados não tinham clareza sobre os objetivos e conteúdos da Educação Musical no contexto escolar, utilizando da música apenas como ferramenta metodológica no ensino de outras disciplinas. A pesquisa contou com o apoio da Secretaria Municipal de Educação de Presidente Prudente que autorizou a participação de seus professores, e possui incentivo do Probic - Unoeste devidamente aprovado pelo Conselho de Ética.

Palavras-chave: Conhecimento Musical, Professor Generalista, Educação Infantil, Ensino Fundamental.

\section{INTRODUÇÃO E OBJETIVOS}

O ensino de música, durante toda a Idade Moderna, caracterizou-se por ser baseado no ensino de instrumentos, regência, harmonia e estudos de composição musical. O resultado dessa forma de selecionar conteúdos e metodologias para o ensino de música concretizou-se nos alunos que eram excelentes compositores, exímios instrumentistas e "bons de ouvido". Havia uma vontade de realçar o talento inato e, portanto, aprender música ficava restrito apenas a alguns alunos que possuíam dom.

No Brasil é importante ressaltar que este paradigma alcançou a contemporaneidade sendo comum a busca pelo ensino musical ser feita em escolas especializadas. No ensino básico a música não conseguiu permanecer de forma efetiva, porém sua tentativa de inserção não é recente. Entre os anos de 1882 e 1883, Rui Barbosa já havia demonstrado preocupação com o ensino de Arte. Seus pareceres sobre Educação incluíram tanto o desenho quanto a música como conteúdos obrigatórios no ensino primário e secundário. É possível verificar, em seus escritos, mais de 90 
páginas dedicadas ao ensino da Arte e, "até hoje nenhum projeto de lei concedeu mais de 50 linhas ao ensino da arte ou ensino do desenho" (BARBOSA, 2006, p. 58). No que se refere à música, Rui Barbosa considerava-a como um conhecimento necessário às crianças e que deveria ser ensinado logo nas séries iniciais, pois sofreu influências das práticas de Kindengarten ${ }^{1}$ européias.

A ideia de incluir a música como conhecimento necessário para a educação integral da criança já constava na proposta para a Reforma do Ensino Primário e Várias Instituições Complementares da Instrução Pública formulada por Rui Barbosa em 1883, e, com o intuito de "cultivar e disciplinar as faculdades morais e intelectuais" indicava o canto, a música e coros para o jardim das crianças, para as escolas primárias elementares, escolas primárias médias e escolas primárias superiores. Para instruir adequadamente os responsáveis pela execução destas propostas, Rui Barbosa organizou um programa de quatro anos para as Escolas Normais Primárias que incluía Pedagogia Geral, Método Fröebel, Aritmética, Geometria e no caso específico da Música, discriminava a Música Vocal, Leitura de Música, Noções essenciais de Teoria, Prática de Violino, para os homens, e Harmônio para as mulheres (JARDIM, 2009, p 17).

Em 1931 o Decreto 19.890 que tornava obrigatório o canto orfeônico nas escolas públicas brasileiras, foi uma tentativa de colocar a música como conteúdo obrigatório. O que foi percebido é que não havia profissionais capacitados para ensinar música nas escolas. Mesmo sendo criado o SEMA (Superintendência de Educação Musical e Artística) em 1932, chefiada por Villa-Lobos no intuito de suprir toda a mão de obra necessária, essas ações não foram suficientes deixando o ensino de música fragilizado. Com a Lei 5692/71, ao implementar a Educação Artística, a música perde forças e sai do cenário escolar prevalecendo as artes visuais, mesmo que o ensino polivalente permitisse sua manutenção.

E o fato é que a música não consegue se inserir de modo significativo nesse espaço, e a prática escolar da Educação Artística, que se diferencia de escola a escola, acaba sendo dominada pelas artes plásticas, principalmente. Vale lembrar que inúmeros livros didáticos de Educação Artística, publicados nas décadas de 1970 e 1980, apresentam atividades nas várias linguagens - artes plásticas, desenho, música e artes cênicas-, embora com predominância das artes plásticas. Além disso, é essa área em que a maior parte dos cursos - e consequentemente dos professores habilitados - se concentra, de modo que, em muitos contextos, arte na escola passa, pouco a pouco, a ser sinônimo de artes plásticas ou visuais (PENNA, 2004, p.22).

\footnotetext{
${ }^{1}$ Jardim de Infância.
} 
A saída da música da escola pode ser atribuída também à dificuldade encontrada pelos professores de acessar cursos de música que eram oferecidos, em sua maioria, no Estado de São Paulo e Rio de Janeiro, deixando os professores dos demais estados por sua própria conta. Assim a linguagem visual, ilustrada em muitos livros didáticos, foi mais facilmente absorvida.

A alteração significativa para a área se deu a partir da Lei 9.394/96 que destituiu o ensino polivalente alterando o nome da disciplina de Educação Artística para Arte. Esta foi então dividida em quatro modalidades artísticas assim nomeadas: Artes Visuais, Música, Teatro e Dança. Apesar da adequação do ensino artístico que agora prevê a atuação de professores com formação específica, o que pode ser percebido na prática ainda é a predominância de conteúdos em Artes Visuais.

Em 2008 a Lei 11.769 foi criada no intuito de recolocar a música como conteúdo obrigatório no espaço escolar. Destarte muitas práticas precisam ser revistas, pois não se trata apenas de ensinar instrumentos musicais a poucos alunos extremamente interessados, mas sim compreender quão amplo é o caminho e qual é realmente a importância do ensino de música na escola.

Apesar de toda dificuldade descrita o ensino de música na Educação Básica não está previsto somente nos Documentos Oficiais ( $L D B, R C N$ ) para o ensino de Arte, Ele aparece também, e na prática bastante presente, nos Documentos ligados a Educação Infantil. Tais documentos como Referencial Curricular Nacional para a Educação Infantil - RCNEI (1998) e nas Diretrizes Curriculares Nacionais para Educação Infantil - DCNEI - (1999) apresentam não só a importância da linguagem musical no desenvolvimento da afetividade, mas também, como é o caso do RCNEl, conteúdos e metodologias a serem adotadas por estes a partir de diferentes justificativas.

O RCNEI, no seu $3^{\circ}$ volume intitulado Conhecimento de Mundo destina 50 páginas para o ensino de música. Nelas é apresentada a música como linguagem, sua importância e função para a Educação Infantil e quais conteúdos podem ser abordados pelos professores. Há também sugestões de leituras de textos sobre o assunto e audição de músicas.

Ouvir música, aprender uma canção, brincar de roda, realizar brinquedos rítmicos, jogos de mãos, etc., são atividades que despertam, estimulam e desenvolvem o gosto pela atividade musical, além de atenderem a necessidades de expressão que passam pela esfera afetiva, estética e cognitiva. Aprender música significa integrar experiências que envolvem a vivência, a percepção e a reflexão, encaminhando-as para níveis cada vez mais elaborados. (RCNEI, 1998, p.46) 
A partir da leitura deste $3^{\circ}$ volume é possível perceber que o texto aborda metodologias atuais em educação musical e critica formas estereotipadas de conceber a música na escola como, por exemplo, usar a música em datas comemorativas, cantar com gestos estandardizados e fazer uso da bandinha rítmica. Por outro lado o documento apresenta diversas abordagens e conteúdos ricos em conhecimento musical e bastante atualizados que, para aborda-los, seria preciso uma significativa formação musical por parte do professor.

Aos poucos, começa a cantar com maior precisão de entoação e a reproduzir ritmos simples orientados por um pulso regular. Os batimentos rítmicos corporais (palmas, batidas nas pernas, pés etc.) são observados e reproduzidos com cuidado, e, evidentemente, a maior ou menor complexidade das estruturas rítmicas dependerá do nível de desenvolvimento de cada criança ou grupo. Além de cantar, a criança tem interesse, também, em tocar pequenas linhas melódicas nos instrumentos musicais, buscando entender sua construção. Torna-se muito importante poder reproduzir ou compor uma melodia, mesmo que usando apenas dois sons diferentes e percebe o fato de que para cantar ou tocar uma melodia é preciso respeitar uma ordem, à semelhança do que ocorre com a escrita de palavras. A audição pode detalhar mais, e o interesse por muitos e variados estilos tende a se ampliar. Se a produção musical veiculada pela mídia lhe interessa, também mostra-se receptiva a diferentes gêneros e estilos musicais, quando tem a possibilidade de conhecê-los. (RCNEI, 1998, p.51) Grifo nosso.

As palavras grifadas na citação acima fazem parte de um conjunto de habilidades musicais que acompanham a formação do músico seja ele instrumentista ou professor de música. São termos que exigem um entendimento conceitual e prático e precisam de tempo para ser desenvolvidos com segurança e maestria. E é a partir do entendimento desta gama de conhecimentos que a música é tratada como linguagem.

Enquanto linguagem, a música pode ser utilizada como um meio afetivo entre professores e alunos e entre os próprios alunos. Nesse sentido, é possível que o professor generalista seja capaz de dominar a linguagem musical de tal forma que possa cumprir os termos previstos pelos documentos oficiais? Apesar de acharmos pouco provável que os professores generalistas recebam em sua graduação uma formação musical tão específica, acreditamos que muitos deles abordem música em suas aulas. Seja cantando para as crianças dormirem, comerem, fazerem sua higiene e mesmo nas brincadeiras, a música está, com certeza, presente nas creches e pré-escolas. Se aspectos criativos acabam por ficar limitados ao usar a música nas aulas, já que não há domínio da linguagem por parte dos professores, a música deve estar fazendo um papel mais afetivo e simbólico que não deixam de gerar significado e são fundamentais na formação do indivíduo. 
Destarte acreditamos que os professores generalistas contribuem para a efetiva presença da música nas escolas. Esses professores são pedagogos e no espaço escolar ocupam, além de cargos de coordenação pedagógica, a regência de sala das turmas do $1^{\circ}$ ao $5^{\circ}$ ano do ensino fundamental. De acordo com Figueiredo (2004)

Em diferentes sistemas educacionais, assim como na literatura, são utilizadas várias denominações para esse profissional: não especialista, unidocente, docente, professor de classe, professor regente, e outros. Apesar da variação de nomenclatura esse profissional é compreendido como sendo aquele responsável pela educação de crianças numa perspectiva integradora, evitando fragmentações curriculares. (p. 54/55)

A presença deste professor em sala é a principal referencia para os alunos nessa faixa etária. Isso porque é com o professor generalista que os alunos iniciam sua vida escolar e aprendem os mais diversos conteúdos. Mesmo que o ensino fundamental ainda conte com o professor de Arte e de Educação Física é o professor generalista que identifica sua turma e a quem seus alunos recorrem nas mais diversas situações. Assim podemos afirmar que os alunos desenvolvem uma relação afetiva com este professor e é nesta figura que mais confiam quando estão na escola, longe de seus pais e de sua casa.

Diferentes conteúdos são abordados pelos professores generalistas de forma lúdica propiciando ambientes prazerosos e como se sabe, ricos em aprendizagem. Dessa forma é possível afirmar que muitos professores utilizam a música em suas aulas seja cantando ou levando músicas gravadas para que os alunos apreciem.

Destarte, este artigo tem o objetivo de compreender como os professores generalistas de algumas escolas municipais de Presidente Prudente desenvolvem música em suas aulas, bem como suas dúvidas e dificuldades.

\section{METODOLOGIA}

Para alcançar tal objetivo, foi elaborada uma entrevista semi-estruturada. Desta forma, as questões foram feitas verbalmente, em uma ordem determinada, compreendendo que, quando houve necessidade, o entrevistador acrescentou perguntas de esclarecimento.

$\mathrm{Na}$ entrevista foram realizadas as seguintes perguntas: Como o professor generalista aborda a música em suas aulas? Esse professor acredita que ensinar música é importante? Este professor já frequentou ou frequenta algum curso de música? Este professor busca fazer cursos de capacitação na área de música? Acha importante ter formação na área? Como a música é ensinada 
também na escola? Tem ciência que o ensino de música é atualmente obrigatório? Quais são suas dúvidas e dificuldades ao falar de música com seus alunos?

Esta entrevista foi realizada com seis professores de escolas tanto centrais quanto periféricas, sendo gravadas e transcritas para análise. O resultado obtido aponta para um possível diagnóstico regional acerca da situação da Educação Musical no primeiro ciclo do ensino fundamental.

\section{RESULTADOS}

Das entrevistas realizadas, 50\% são de professores que lecionam em escolas centrais da cidade e outro $50 \%$ são de professores que lecionam em escolas da periferia da cidade. Apenas duas professoras nunca tiveram contato com música, seja na infância ou como curso de capacitação profissional. Os demais professores afirmaram ter estudado música ou algum instrumento musical quando adolescentes ou afirmaram terem feito curso de capacitação em Educação Musical, promovido pela Secretaria Municipal de Educação ou por instituições particulares.

E, analisando os conteúdos das entrevistas, foram percebidos os seguintes pontos em comum nos discursos: 0 ensino de música limitado ao estudo técnico de instrumento musical, compreensão musical restrita ao sistema tonal (sistema musical predominante na cultura de massa), utilização da música como ferramenta de ensino de outros conteúdos curriculares não musicais, a música como prática de civismo e para promover festas comemorativas, e música ensinada em forma de projetos e não como conteúdo curricular.

O primeiro ponto identificado foi que o ensino de música é limitado ao estudo técnico de instrumento musical. Todos os entrevistados relacionaram o ensino efetivo de música ao aprendizado da técnica de um instrumento musical. Quando questionados sobre "como você aborda música na sua aula?", responderam usando termos como "nós achamos que cantar uma musiquinha já é trabalhar música, mas na verdade não é, tem que ter um pouco de conhecimento dos instrumentos, da técnica para poder ensinar a criança"; ou então "Quando você ensina pra criança pequena, você ensina na informalidade [cantar], agora, pra essa formação mesmo de 'educação musical', eles aprendendo a música propriamente dita, tem que ter um relacionamento com os instrumentos musicais".

Como segundo ponto identificado na fala dos professores foi que sua compreensão musical é restrita ao sistema tonal. Muitos professores citaram elementos da música tonal 
quando questionados sobre "o que é ensinar música", nos termos "não é só cantar, é ensinar melodia, ritmo, compasso, tempo forte". Além disso, citaram estilos musicais como Funk, MPB, chorinho, e músicos como Richard Clayderman, evidenciando que o conhecimento de música se resume a músicas tonais. Nesse sentido, outras abordagens estéticas como, por exemplo, a audição de Paisagens Sonoras proposta por Schafer $(1991,2001)$ ou ainda utilizar o ruído seja no conteúdo ou em sua metodologia foram descartados pelos professores entrevistados.

Um terceiro ponto identificado foi que a música é utilizada como ferramenta de ensino de outros conteúdos curriculares não musicais. Respondendo à mesma pergunta sobre "o que é ensinar música", todos os professores afirmaram que o objetivo principal da música é servir de lúdico para socializar e alfabetizar: "Eu pesquiso músicas para a faixa etária deles, pra criança aprender mesmo, tanto o letramento quanto outras áreas.", ou "Usamos a Terezinha de Jesus para ensinar números ordinais".

O quarto ponto indica que, para os professores entrevistados, a música é utilizada como prática de civismo e para promover festas comemorativas. Questionando sobre "como a escola ensina a música" alguns professores responderam que semanalmente e nas datas cívicas os alunos cantam o hino nacional e municipal.

O quinto e último ponto identificado foi que a música é desenvolvida em forma de projetos e não como conteúdo curricular. Algumas escolas visitadas apresentam jornada integral e contam com o auxilio de projetos como, por exemplo, o projeto municipal Cidade Escola, que ensina música e esportes, contudo não fazendo parte do ensino formal. Na área musical, são desenvolvidas bandas marciais, corais, ensino de instrumento específico (violão, violino e flauta doce). No ensino formal cada professor ensina música (quando ensina) em sua aula de forma livre, abordando os conteúdos (melodia, compasso e ritmo) que acha importante.

\section{DISCUSSÃO}

Todas estas questões demonstram que, apesar de ter ciência da Lei 11.769/08, os professores não tem conhecimento sobre o efetivo papel da Educação Musical na escola e nem dos conteúdos musicais que devem ser desenvolvidos com os alunos. Diante da obrigatoriedade, os professores introduzem a música em seu ambiente escolar da forma que julgam melhor, seja usando a música como ferramenta para ensinar português, matemática e interpretação de texto, entre outros conteúdos curriculares, seja incentivando a execução dos hinos pátrios, ou, seja levando as crianças a cantarem e tocarem instrumentos de bandinha rítmica. 
Outro aspecto importante a ser ressaltado é que a fala dos professores entrevistados mostra que existe não só uma leitura dos Documentos Oficiais, ainda que o olhar focasse somente nos conteúdos, mas também uma busca particular na internet e outros materiais didáticos, pois falar em melodia, ritmo, tempo forte, compasso, ressaltar a importância de saber tocar um instrumento musical, achar que cantar uma musiquinha não é aula de música ou ainda expressar opinião sobre estilos musicais como Funk, MPB, entre outros mostrou que esses conteúdos foram absorvidos a partir diferentes leituras.

\section{CONCLUSÃO}

É grande ainda o caminho para que a música ocupe seu lugar verdadeiro no espaço escolar. Os cursos de capacitação de professores precisam ser revistos, pois temos ciência que os conteúdos e metodologias apresentados nos Documentos Oficiais tais como LDB, PCN, RCN, RCNI, exigem uma formação musical do professor generalista que jamais será alcançada. É claro que aulas de música devem ser dadas por professores licenciados para tal, mas acreditamos que, atualmente, é o professor generalista quem vai contribuir diretamente com a permanência efetiva da música na escola. Precisamos sim de todo apoio possível.

Nesse sentido existe uma infinidade de metodologias e conteúdos em música que, partindo de propostas lúdicas, alcançam melhores resultados sabendo que os professores generalistas não tem formação musical. Uma delas é ampliar a concepção estética destes professores para a música contemporânea e compreender que música não é feita somente de alturas definidas e métrica. Jogos envolvendo ruídos e incentivo à percepção auditiva para a Paisagem Sonora que nos cerca são propostas que podem trazer melhores resultados tanto para os alunos quanto aos professores.

Incentivar a música no ambiente escolar é importante, mas é necessário repensar o papel de uma Educação Musical no ensino formal. De todas as artes, a música é a única que tem obrigatoriedade por lei de estar inserida nos planejamentos escolares. Uma vez que os professores licenciados em música não conseguem atender a demanda de todo a rede de ensino, é fundamental contar com o trabalho de professores generalistas.

\section{REFERÊNCIAS}

BARBOSA, Ana Mae. Arte-educação no Brasil. São Paulo: Perspectiva, 2006. 
BRASIL. Ministério da Educação e do Desporto. Referencial Curricular Nacional para a Educação Infantil. Brasília: MEC/SEF, 1998.

. Resolução CEB 1/99. Diretrizes Curriculares Nacionais para Educação Infantil.

FIGUEIREDO, Sérgio Luiz Ferreira de. A preparação musical de professores generalistas no Brasil. Revista da ABEM, Porto Alegre, V. 11, 55-61, set. 2004.

JARDIM, V. L. G. Institucionalização da profissão docente - o professor de música e a educação pública. Revista da Abem, Porto Alegre, V.21, 15-24, mar. 2009.

MANZINI, E.J. Considerações sobre a elaboração de roteiro para entrevista semi-estruturada. In: MARQUEZINE: M. C.; ALMEIDA, M. A.; OMOTE; S. (Orgs.) Colóquios sobre pesquisa em Educação Especial. Londrina:eduel, 2003. p.11-25.

PENNA, Maura. A dupla dimensão da política educacional e a música na escola: Analisando a legislação e termos normativos. Revista da ABEM, Porto Alegre, V. 10, 19-28, mar. 2004. 